\title{
Hydro-Sedimentary Dynamics of the Grand-Popo Lagoon Located Upstream of the Mobile Embouchure "Bouche du Roy" in South-Western Benin
}

\section{Honorin Gbinibou Andemi', Gérard A. F. d'Almeida', Moussa Bio Djara1, Léandre Accalogoun², Rodrigue A. Adechina ${ }^{1}$, Christophe Kaki ${ }^{1}$}

${ }^{1}$ Laboratory of Geology, Mines \& Environment (Labo, GME), Department of Earth Sciences (DES), University of Abomey-Calavi, Cotonou, Benin

${ }^{2}$ ACL Consultant: General Engineering Design Office, Cotonou, Benin

Email: gbinibouhono@gmail.com

How to cite this paper: Gbinibou Andemi, H., d'Almeida, G. A. F., Djara, M. B., Accalogoun, L., Adechina, R. A., \& Kaki, C. (2021). Hydro-Sedimentary Dynamics of the Grand-Popo Lagoon Located Upstream of the Mobile Embouchure "Bouche du Roy" in South-Western Benin. Journal of Geoscience and Environment Protection, 9, 98-112.

https://doi.org/10.4236/gep.2021.911008

Received: October 14, 2021

Accepted: November 26, 2021

Published: November 29, 2021

Copyright $\odot 2021$ by author(s) and Scientific Research Publishing Inc. This work is licensed under the Creative Commons Attribution International License (CC BY 4.0).

http://creativecommons.org/licenses/by/4.0/

\begin{abstract}
The problems of flooding, bank erosion and even the breaching of the barrier beach by the Grand-Popo lagoon are a concern in the south-western Beninese river-lagoon complex. The present study aims to improve the knowledge of the factors controlling the hydro-sedimentary functioning of this lagoon of Grand-Popo. It was based on bathymetric and sedimentological studies and the analysis of physical-chemical parameters of the water and allowed to know the morphology of the lagoon bottom and the distribution of sedimentary facies according to the intensity of the water current. The salinity of the lagoon waters shows a west-east gradient passing thus from $0 \%$ to $0.78 \%$ in the main direction of flow. Over the whole lagoon system, the average liquid flows vary from -38.499 to $159.13 \mathrm{~m}^{3} / \mathrm{s}$. The bathymetry indicates depths varying from 0.4 to $6.5 \mathrm{~m}$, revealing type $\mathrm{V}$ and type $\mathrm{U}$ lagoon bottoms which reflect acute bottom concavities marked by hollowing under the effect of strong currents or by sandy terraces resulting from the continuous input of sediments carried by the Mono River. These sediments are heterogeneously distributed in the lagoon bottom and vary from free sand to mud. Given the complexity of the factors that control the hydro-sedimentary functioning of the Grand-Popo lagoon, it is recommended that periodic hydrological and bathymetric monitoring be carried out to locate exceptional variations in water levels to prevent not only the risks of overflowing lagoon waters and the flooding that follows but also spectacular erosion of the lagoon banks.
\end{abstract}




\section{Keywords}

Grand-Popo Lagoon, Hydro-Sedimentary Functioning, Lagoon Bottoms, Sediments

\section{Introduction}

Lagoons are elongated bodies of water located between the mainland and a barrier beach, generally pierced by channels, and they appear to be highly evolving coastal systems dependent on multiple natural and anthropogenic factors. These paralic environments reveal a great variability of hydrodynamic and sedimentological conditions, a rapid evolution of their morphological framework and a great vulnerability (Maanan, 2003). These areas are of economic expansion where a thorough knowledge of their functioning is essential for rational exploitation.

In Benin, the coastal lagoon is the longest paralic water body with a length of about $55 \mathrm{~km}$. The western part of this coastal lagoon is called the Grand-Popo lagoon and the eastern part is called the Ouidah lagoon (Kombieni, 2016). They belong to the southwestern Beninese river-lagoon complex comprising the Lower Mono, the Aho Channel, Lake Ahémé and the coastal lagoon itself. Since the construction of the Nangbeto dam on the Mono River, the Granp-Popo lagoon ecosystem has undergone significant changes in its hydrological and sedimentological regime, resulting in spectacular erosion of the banks and periodic flooding of the surrounding localities (Rossi, 1996). Despite these multiple imbalances observed in this lagoon ecosystem, no study has addressed the factors that govern the hydrodynamic and sedimentary functioning of this lagoon. This justifies the present study whose main objective is to analyze the hydro-sedimentary functioning of the Grand-Popo lagoon which has an important socio-economic interest. It will be based on bathymetric, hydrological and sedimentological campaigns and measurements of physico-chemical parameters of the lagoon water.

\section{Study Area}

The study area is located in the municipality of Grand Popo, bordered by municipalities of Athiémé, Comé and Houéyogbé to the north; Ouidah and Kpomassè to the south-east; the Republic of Togo to the west and by the Atlantic Ocean to the south. It lies between $1^{\circ} 35^{\prime}$ and $1^{\circ} 58^{\prime}$ East longitude and between $6^{\circ} 10^{\prime}$ and $6^{\circ} 30^{\prime}$ North latitude (Figure 1).

The study area belong to the Mono-Couffo estuarine system, which includes the lower Mono river, the coastal lagoon, the Aho channel and Ahémé lake, all associated with a very thick network of anastomosing tidal channels often bordered by mangroves. This coastal lagoon is made up of a narrow channel with a maximum width of $500 \mathrm{~m}$ which stretches parallel to the coast from the village of Agbanakin (in the vicinity of Grand-Popo) in the west to the village of Dondji 


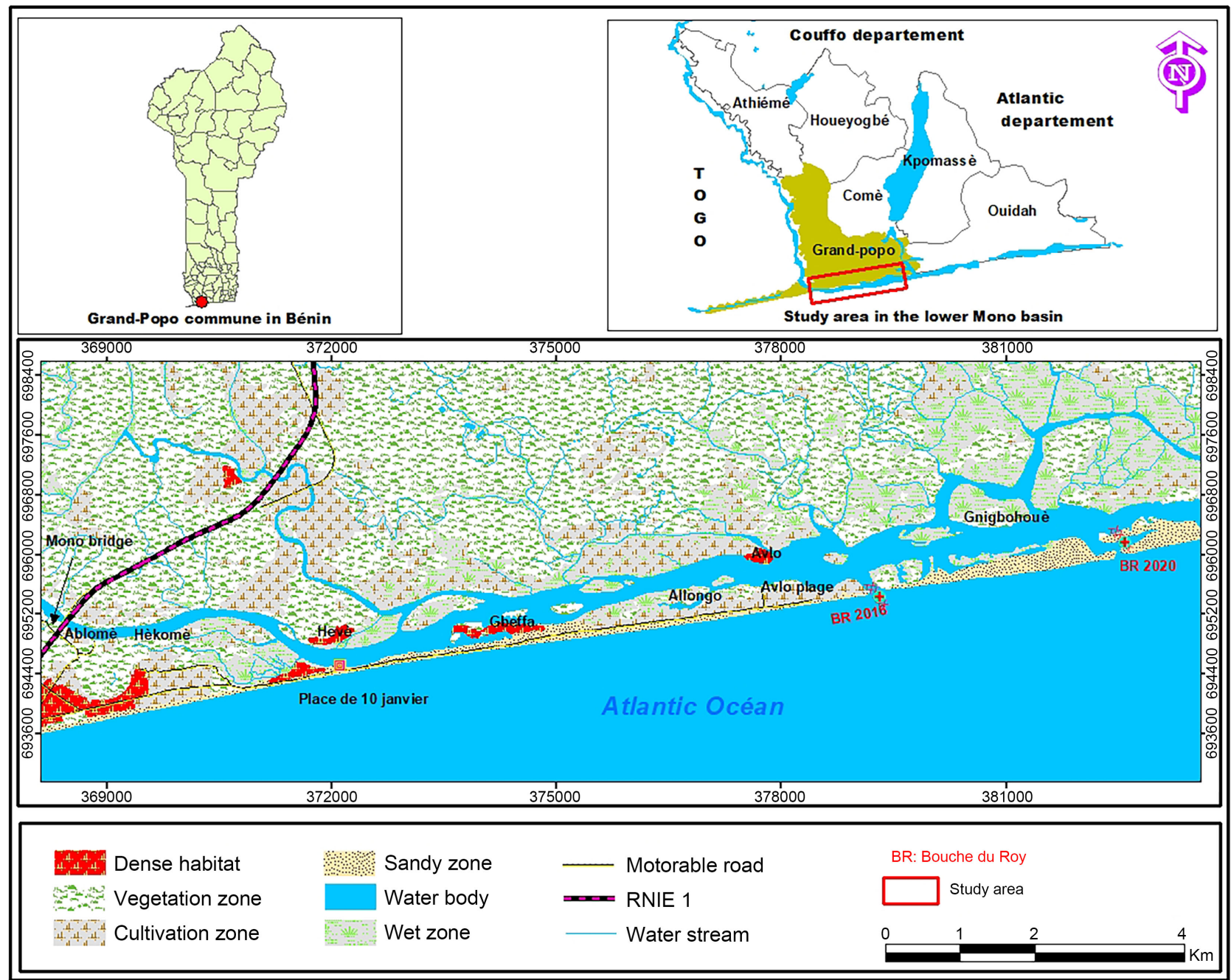

Figure 1. Location of the study area.

in the east. It is fed by the Mono river and its tributary the Sazoue and connected to Ahémé lake by the $10 \mathrm{~km}$ long Aho channel (Norda Stello et BCI Consults, 2016).

On climatic point of view, the area is characterized by a long dry season (with less than $40 \mathrm{~mm}$ of rainfall in November, December, January and February), a long rainy season (April, May, June, July), a short rainy season in October and a short dry season in August. The average temperature variation measured the Bohicon and Ouidah stations shows that the annual average is $27.2^{\circ} \mathrm{C}$ during dry season and $26.5^{\circ} \mathrm{C}$ during rainy season (ADELAC, 2019). In the study area, the predominant oceanic winds come respectively from the South-West (64\%), the West-South-West (16\%) and the South-South-West (14\%) (ACL Consultant, 2016). They generate semi-waves which are responsible for the accumulation of sandy facies on the north-eastern shores of the water body while the southern shores of the water body are covered with sandy facies (Oyédé et al., 2007).

From geological point of view, the study area is characterised by the presence 
of recent deposits of Quaternary ages (Kaki et al., 2001). It is located in the coastal plain, which is made up of three generations of sandy strips inherited from the marine oscillations of the recent Quaternary (Oyédé, 1991). These are the internal yellow sand bars, the median grey sand bars, and the present and sub-actual brown sand bars.

\section{Methodological Approach to the Study}

The methodological approach adopted took into account data collection during field campaigns followed by laboratory data processing.

\subsection{Field Campaigns}

These campaigns concern the measurements of physico-chemical parameters, bathymetric and flows.

\subsubsection{Measurements of Physico-Chemical Parameters}

These measurements were taken at sediment sampling stations to better understand the hydrological dynamics of the lagoon. The apparatus used was the "Multi 3630 IDS WTW" multiparameter. In total, sixty-four (64) points were sampled on the lagoon. For each point of sampling, geographical coordinates were recorded using a GPS. Measured parameters were: salinity, conductivity, $\mathrm{pH}$ and total dissolved solids (TDS). All measurements were taken $50 \mathrm{~cm}$ below water surface.

\subsubsection{Bathymetric Measurements}

These were carried out on the coastal lagoon using a dual-frequency echo sounder. The echo sounder is mounted on a motorised boat and fixed against it to take measurements along transects (Figure 2) positioned with a GPS plotter and equidistant from each other by three hundred (300) metres. Thus, the probe determines the depth corresponding to each of the points during the probe path.

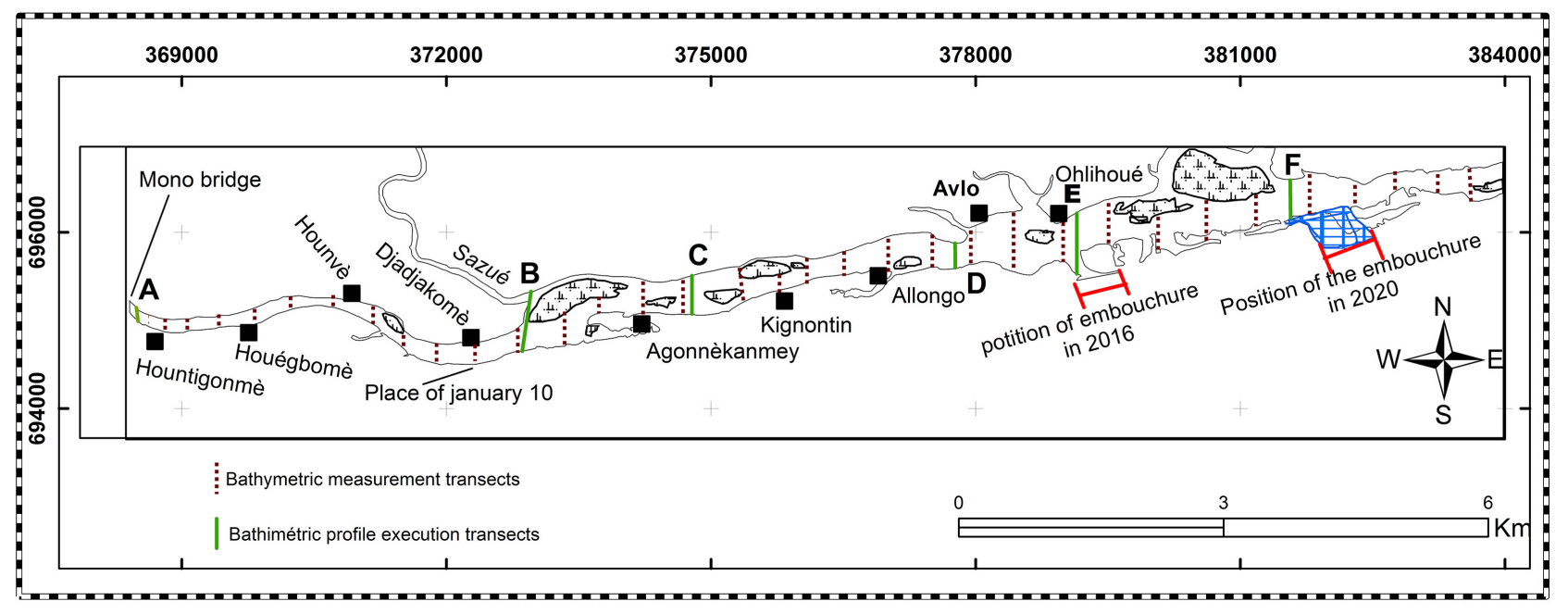

Figure 2. Map showing position of bathymetric measurement transects used for the execution of bathymetric profiles. 


\subsubsection{Flows Measurements}

These measurements were carried out using an ADCP along 14 predefined transects and positioned according to the hydrological contexts, particularly in the confluence and mouth areas. The measurement of the current velocity direction is based on the acoustic energy reflected by the particles suspended in the water (Figure 3).

\subsection{Data Processing}

\subsubsection{Processing of Bathymetric Data}

Using Excel software, the raw files, obtained during the bathymetric surveys, were converted into usable files. With ArcGIS 10.2 software environment, the sampling points marked in UTM coordinates were projected onto a topographic background, from which the lake contours were extracted. The coordinates of the measurement points were juxtaposed with bathymetric and sedimentological data to produce bathymetric and sedimentological maps. The interpolation method used to produce these two digital terrain models (bathymetric and sedimentological maps) is kriging by spatial autocorrelation. This method consists of estimating the attribute value for non-sampled sectors located within the limits defined by the positions of the sampled points. The kriging treatment gives the least distorted results, whatever the type of point seedings entered. To complete the operation, the bathymetric point sets are processed using Surfer 11 software, which allows the $3 \mathrm{D}$ representation of a digital terrain model (DTM), as well as the drawing of profiles following well-identified points.

\subsubsection{Processing of the Sediment Samples}

The sampled sediments were first described macroscopically on the field and further in the Laboratory of Geology, Mines and Environment (LGME) of the University of Abomey-Calavi. The granulometric data were processed graphically and numerically.

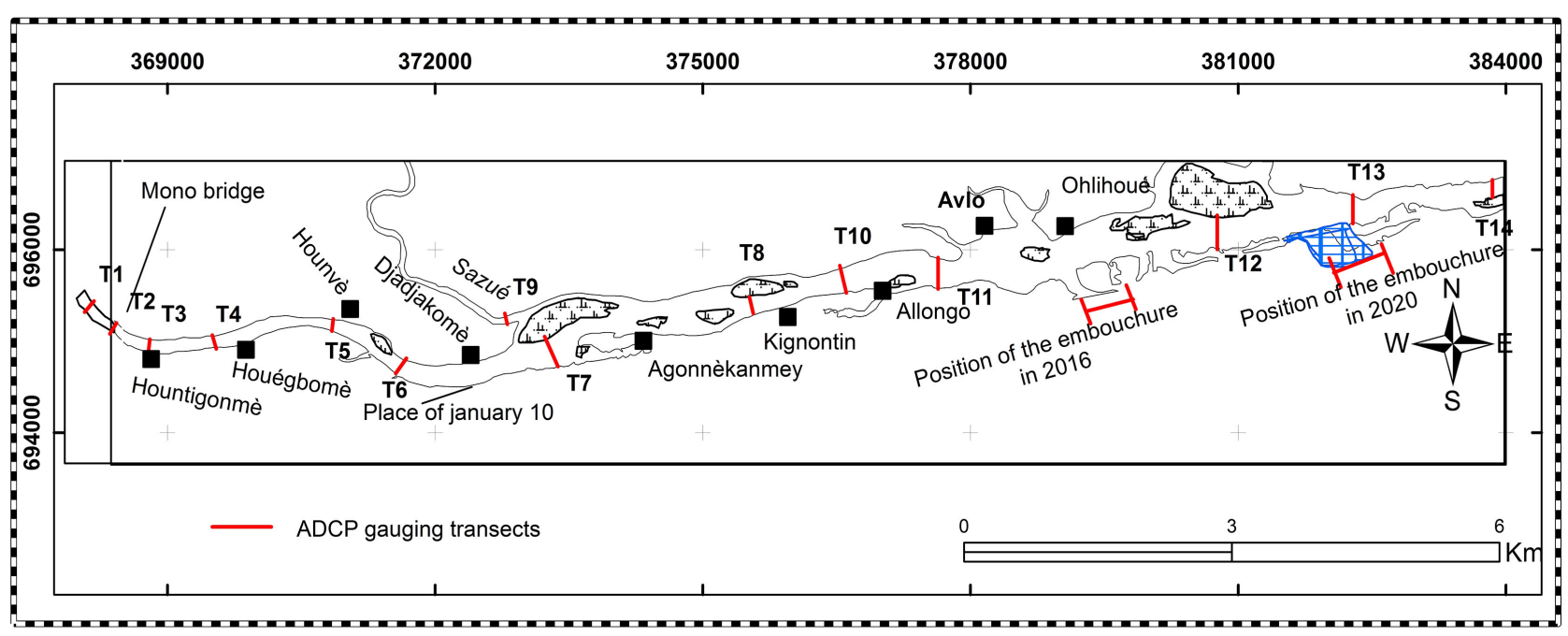

Figure 3. Map showing the position of transects (T1 to T14) for current measurements at the ADCP. 


\section{Results and Discussion}

To understand the hydro-sedimentary functioning of the Grand-Popo lagoon, it was necessary to appreciate first the spatial variation of the physico-chemical parameters of the water, then the morphological characteristics and the spatial distribution of the facies in the lagoon and finally, to analyze the hydrodynamic forcing responsible of sediment deposition in this lagoon.

\subsection{Spatial Variation of the Physico-Chemical Parameters of the Water}

\subsubsection{Variation in Water Salinity}

The water salinity varies with an increasing gradient from West to East mainly related to the hydrological regime of the lagoon. Salinity values are zero on the west side but reach $0.78 \%$ o in the central part of the lagoon with an average of $0.24 \%$. On the other hand, it increases from $0.78 \%$ o to a maximum value of $7.1 \%$ near the embouchure gateway (Figure 4). This variation can be easily explained by the inflow of continental water from the Mono especially during the flood period which softens the lagoon waters whose salinity is induced by the marine waters.

\subsubsection{Variation in Water Conductivity}

The water conductivity shows the same spatial variation as the salinity, with values varying between 3.5 and $639 \mu \mathrm{S} / \mathrm{cm}$ (Figure 5), and an average value of $210.30 \mu \mathrm{S} / \mathrm{cm}$. The waters have a moderately mineralised character towards the east, from Allongo to the mouth. On the western side, the water is poorly mineralised and acquires a dulcification at the level of the bridge under the effect of the inflow of the Mono River into the lagoon.

\subsubsection{Variation in Total Dissolved Solids}

Total dissolved solids (TDS) show a similar variation to conductivity and salinity. The TDS values of the lagoon waters vary between 3.50 and $640 \mathrm{mg} / \mathrm{l}$ with an average of $208.86 \mathrm{mg} / \mathrm{l}$ (Figure 6).

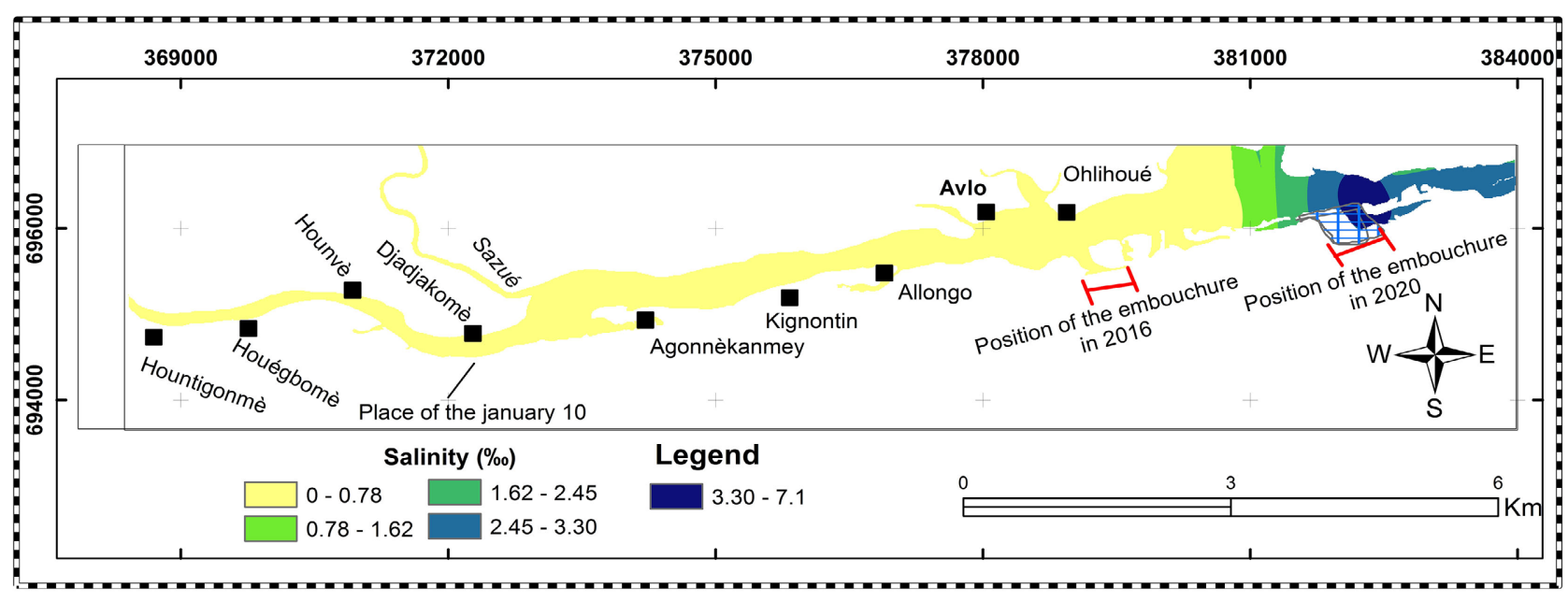

Figure 4. Map of salinity variations of surface waters in the Grand-Popo lagoon. 


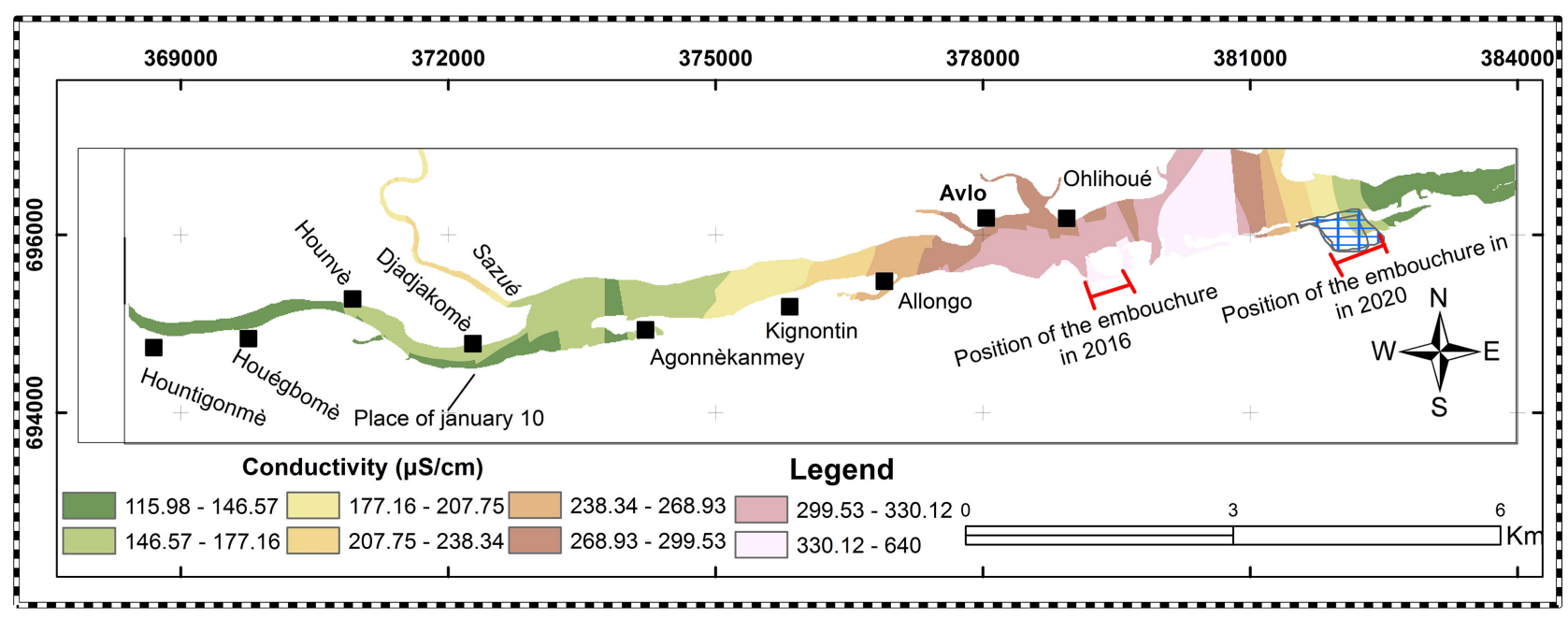

Figure 5. Map of variation of surface water conductivity in the Grand-Popo Lagoon.

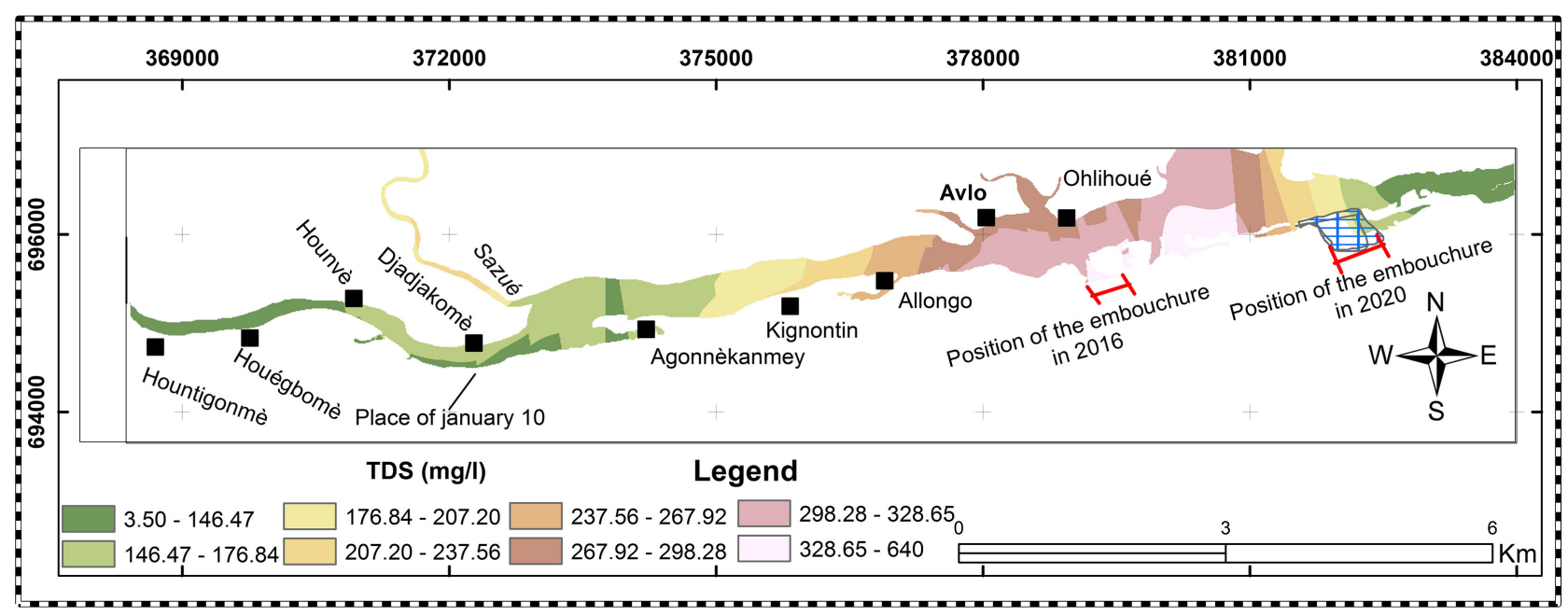

Figure 6. Map of TDS variation of surface waters in the Grand-Popo lagoon.

\subsection{4. $\mathrm{pH}$ Variation}

The $\mathrm{pH}$ values of the waters in the Grand-Popo lagoon vary from 7.2 in the West to 7.9 in the East. Overall, the waters are not very basic, this indicates intense biological activity in the lagoon and the influence of more basic marine waters with $\mathrm{pH}$ values of $8.14-8.25$ (Figure 7). Drainage water from the plain downstream of the Mono, which is very marshy, is rich in organic matter and likely enriches the water with organic acids (Figure 7).

\subsection{Hydromophological Characteristics of the Grand-Popo Lagoon}

The bathymetric map reflects the layout of the sediments at the bottom of the water body. It reflects the sedimentological evolution between measurements of two different periods. The various channels associated with the lagoon are not taken into account in this study. The bathymetric map shown in Figure 8 is realized with made measurements. The analysis of Figure 8 shows that the bottom 


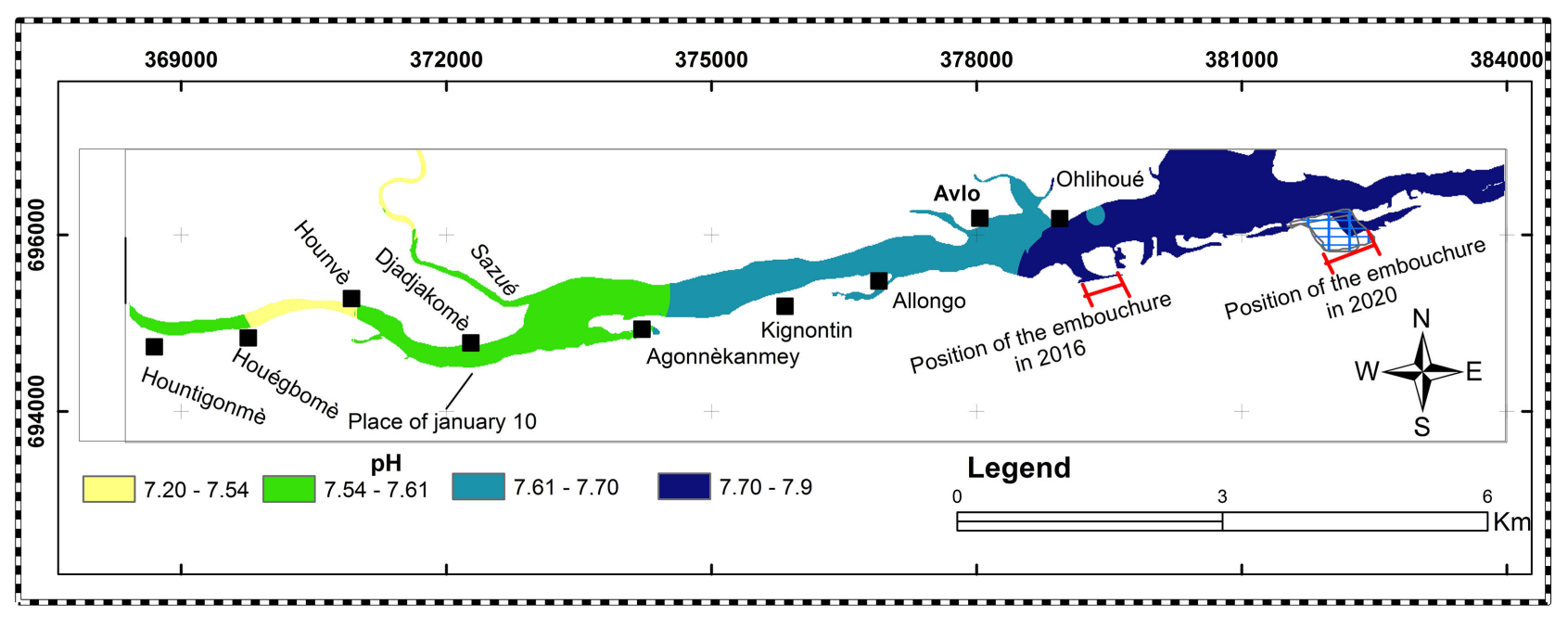

Figure 7. Map of $\mathrm{pH}$ variation in the surface water of the Grand-Popo lagoon.

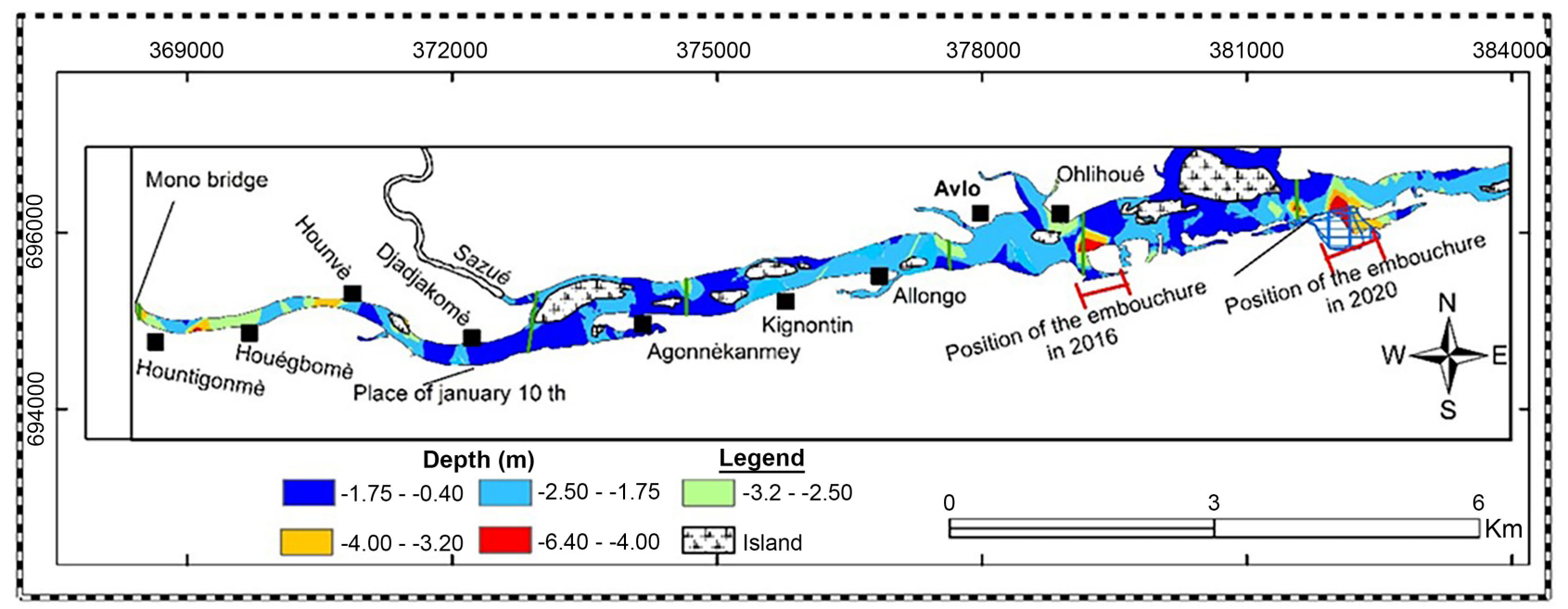

Figure 8. Bathymetric map of the Grand-Popo lagoon.

depths vary from 0.40 to $6.5 \mathrm{~m}$. These bottoms of the Grand-Popo lagoon are divided into five categories according to depth.

\section{- Beds between $0.4 \mathrm{~m}$ and $1.75 \mathrm{~m}$ deep}

They represent the major part of the lagoon's extent, showing a flat configuration. These shallower depths are generally identified towards the edges of the lagoon and around the islets...

\section{- Beds between $1.75 \mathrm{~m}$ and $2.5 \mathrm{~m}$ deep}

They occupy most of the central part of the Grand-Popo lagoon between Kingnontin and Avlo, then the east of the current embouchure.

\section{- Beds between $2.5 \mathrm{~m}$ and $4 \mathrm{~m}$ deep}

These bottoms are identified on the western side of the lagoon and reflect the erosive action of the currents of the Mono River as it enters the lagoon.

\section{- Beds between $4 \mathrm{~m}$ and $6.4 \mathrm{~m}$ deep}

These bottoms show the greatest depths of the lagoon and are characterized by a small extension. They are in the form of basins located at the embouchure 
of the "Bouche du Roy".

To analyze the morphology of the seabed transects oriented North-South has been positioned (Figure 2), along which bathymetric profiles are made.

In general, the lagoon channel shows an irregular transverse profile with steep sides. Figure 9 shows that the bottoms are essentially made up of three morphological types: the "V" type, the " $U$ " type and the intermediate type. These profiles, therefore, provide information on the dominant phenomena in the different sectors.

The "V" type is very characteristic of the sectors adjacent to the embouchure opened in November 2016, those close to the current mouths of the Bouche du Roy and the Sazué, notably to the east of the Place of January 10th du (profiles B, $\mathrm{E}$ and F). These types of channels are concave with a sharp bottom. They reflect erosion that is due to certain factors such as currents and relief. We, therefore, have an erosion-transport phenomenon. The action of erosion is intense in these areas and accentuates the differences in level.
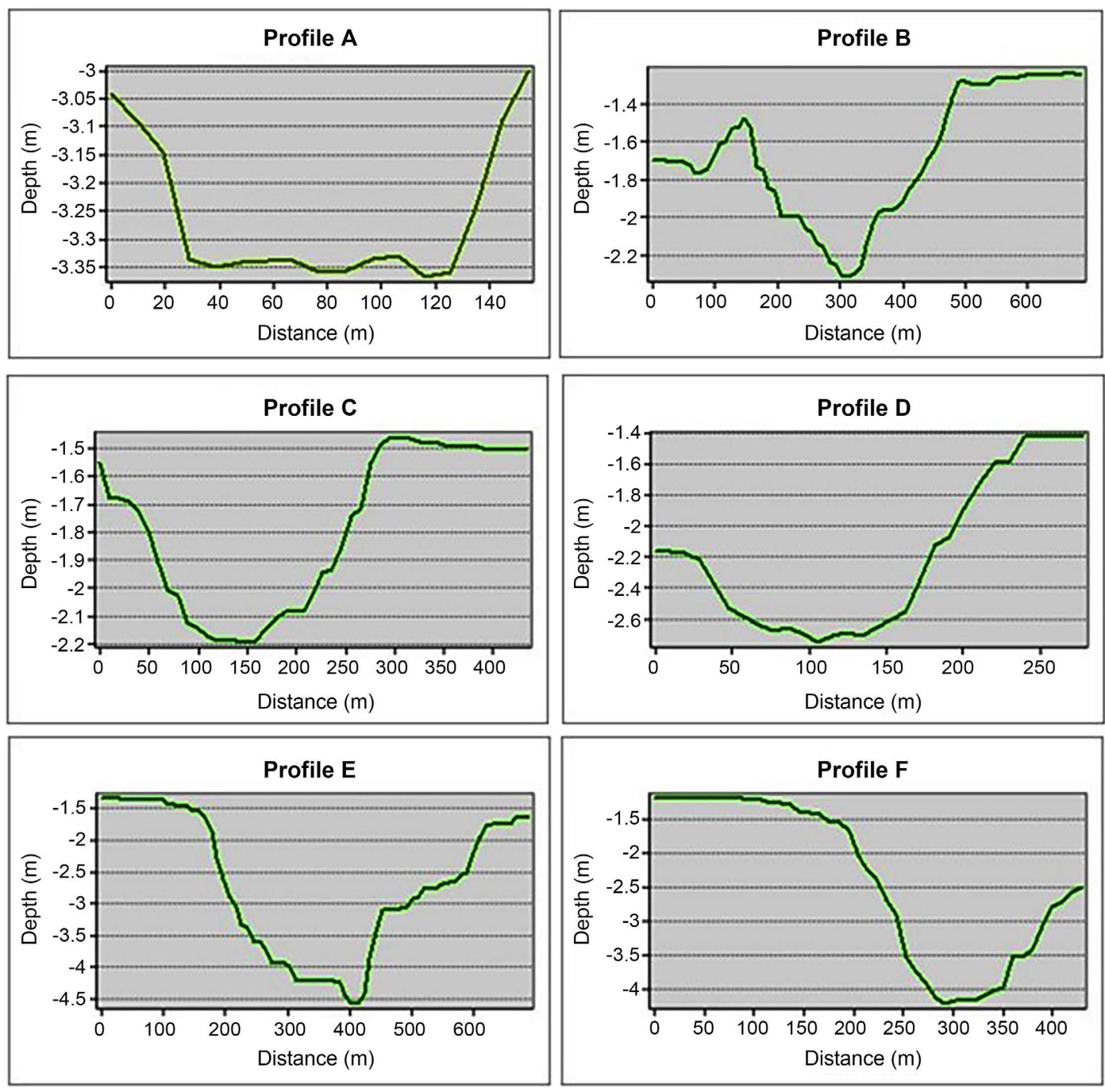

Figure 9. Bathymetric profiles of the bottom of the Grand-Popo lagoon. 
The bottoms of the sectors located near the Mono (profile A); present" U" type morphology with steep sides and a more or less monotonous or almost flat morphological bottom. They are characterized by a continuous supply of sediment from the Mono. This morphological type is concave or U-shaped, i.e. flared and flattened at the bottom. It should be noted that channels with a "V" profile are progressively transformed under the effect of the transport-deposition phenomenon to adopt a definitive " $U$ " profile. The " $U$ " profile is an equilibrium profile of action between the accumulation agents and the erosion agents. However, further erosive action can resume and start the excavation work again.

The bottoms of the sectors near Avlo and Agonnékanmè (profiles C and D) show an unexpectedly flat bottom trend. Their profile suggests an intermediate profile that has not yet reached its equilibrium form or has reached it and subsequently undergone a new phase of erosion or sediment accumulation. These bottom morphologies can be explained by hydrodynamic variations, the presence of numerous islands and anthropic developments in the lagoon.

\section{Variation of Flows and Distribution of Current Water}

The average flows vary from -38.499 along transect $\mathrm{T} 12$ to $159.13 \mathrm{~m}^{3} / \mathrm{s}$ along transect T8 (Figure 10). The negative values of the flows are explained by the reversal of the water flow direction due to the daily variation of the tide.

\subsection{Lithofacial Characteristics of the Lagoon Floor}

The bottom sediments of the Grand-Popo lagoon are divided into four typical facies: clear sand facies, muddy sand facies, sandy mud facies and mud facies. The distribution of lithofacies in the Grand-Popo lagoon is shown in Figure 11.

Sand facies: this is the most widespread facies in the Grand-Popo lagoon. It occurs in a west-east band at the bottom of the lagoon and largely occupies the northern edge of the brown sand bar at the localities of Hountigonmè and Kingnontin; then from Avlo to the east of the present embouchure namely "Bouche du Roy". On the northern edge of the lagoon, it represents a vast floodable terrace covered with vegetation and often interrupted by fine sediment facies. These sands are generally brown to grey-brown, fairly clean and sometimes containing shells of lamellibranchs and gastropods. Macroscopically, they are fine to medium sands and medium sands. Deposits of fine sands containing small white mica flakes are locally identified on the north bank, near the mouth of the Sazué and Houndjohoundji rivers.

Facies of muddy sands: its extension is limited to the north of the lagoon, and covers the corridor bordering the village of Gnigbohoue as far as the mouth of the Dohimè River. They also run along the edge of the shrubby savannah and mangrove developed at the expense of the brown sandy strip of the Avlo Houta village. Their extension is reduced towards the entrance of the Mono into the lagoon. The sand contained in this facies is essentially fine and medium, dark grey. 


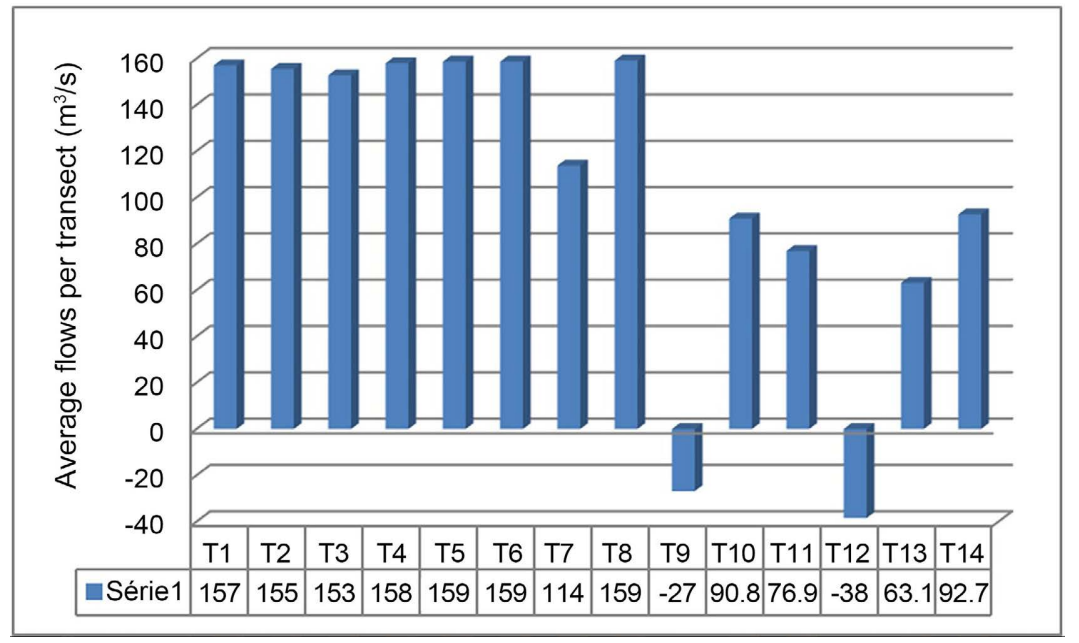

Figure 10. Average flows measured per transect at the ADCP.

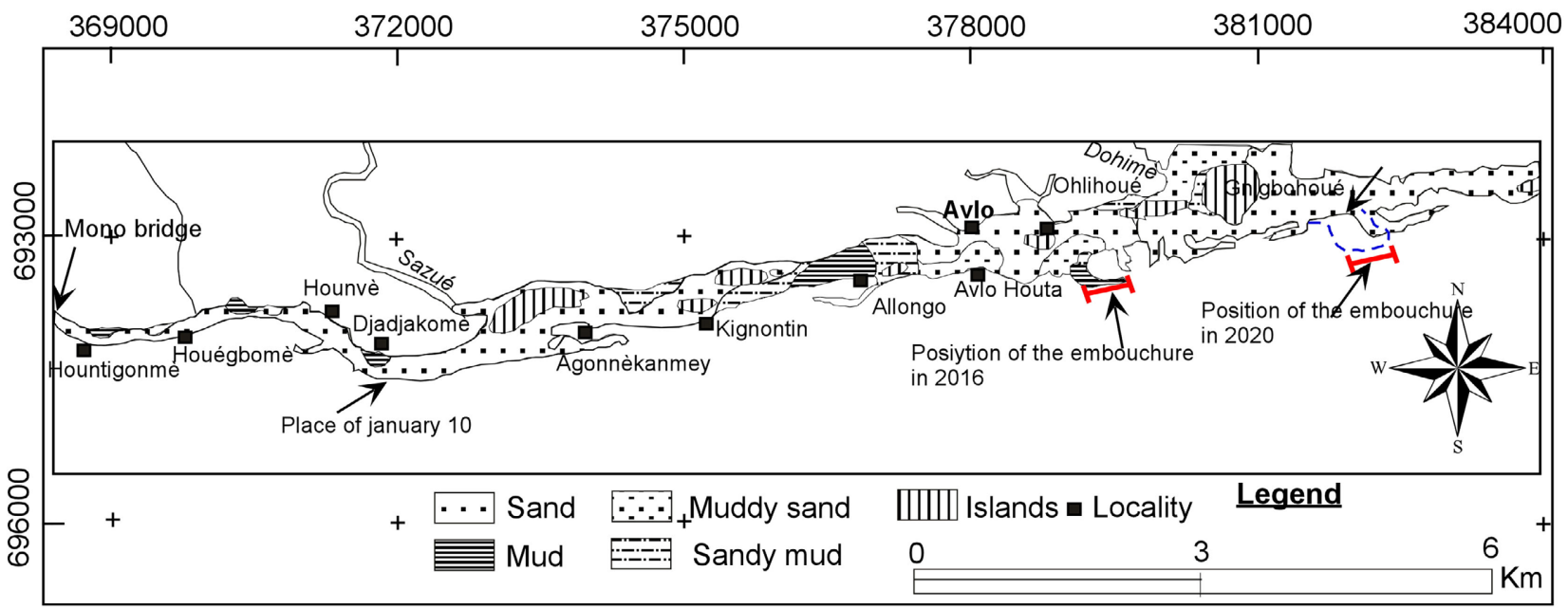

Figure 11. Lithofacies map of the Grand-Popo lagoon.

Facies of sandy muds: This is present in the extension of the muddy sands deposited at the mouth of the Dohimè river in the lagoon. It is particularly developed in the central part of the Grand-Popo lagoon between the villages Kingnontin and Allongo, where it is found around the muddy facies. It is more than a kilometre long on both sides of the muddy facies. It is black and contains abundant plant debris.

Muddy facies: small patches of mud have been identified on the northern edge of the lagoon near the locality of Djadjakomè. Greenish-grey in colour, sometimes blackish, this facies contains abundant gastropod shells. Its greatest extension is noted between the sandy muds identified near the villages of Kingnontin and Allongo. It lines the bottom of the basin formed following the closure of the mouth in November 2016.

Although the fine facies identified on the northern edge do not have a wide enough extension, the spatial distribution of the lithofacies in the Grand Popo lagoon reflects the hydro-sedimentary processes that take place in the paralic ba- 
sins open to the sea and which show a longitudinal gradient from sandy deposits to the sea and from clayey-muddy deposits to the land.

\subsection{Morphological Characteristics of the Study Area}

\section{Topography of the Lagoon Floor}

The lagoon has significant morphological variations with shoals and depressions (small basins) within the channel. One can distinguish the presence of a deeper "furrow" that runs along the island of the village Gnigbohoué. This furrow would reflect either the influence of the deepening of the bottom during the migration of the mouth between 2016 and 2020. The digital terrain model of the Grand-Popo lagoon bottom is shown in Figure 12

\section{Discussion on Hydrological and Sedimentary Dynamics}

The analysis of the hydro-sedimentary dynamics is based on the results of the sedimentology, bathymetry and currentometry data. This analysis is presented by sector of the lagoon.

\section{- Sector from the bridge to the Place of January 10th}

The analysis of the bathymetry and the morphology of the lagoon bottom shows that at the e trance to the Mono, the bottom has an almost flat morphology with steep sides and depths ranging from 2.5 to 4 metres. In this western part of the lagoon, there is first a progressive decrease of the water flow after the bridge ( 157 to $153 \mathrm{~m}^{3} / \mathrm{s}$ ), then an increase of the flow west of the Place of January 10 th $\left(159 \mathrm{~m}^{3} / \mathrm{s}\right)$.

Although the lagoon morphology at the entrance to the Mono suggests a certain equilibrium over time, small ripples lining the "U" shaped bottom would indicate a resumption of the digging activity by the Mono currents. The distribution of water speeds shows very rapid surface currents with high speeds (over $1.43 \mathrm{~m} / \mathrm{s}$ ), and an angle of attack towards the beach strip, the edge of which has a concavity characteristic of eroding banks. These currents have the same intensity of attack on the beach sands located on the western side of the Place of January $10^{\text {th }}$.

From a sedimentological point of view, the sedimentary facies are made up of medium sands, except for fine deposits of gastropods, locally identified on the northern edge of the lagoon near the locality of Djadjakomè, Hounvè and to the north of Hountigonmè (Figure 11). The deposition of these fine facies on the northern edge is linked to the morphology of the lagoon floor and banks. The lagoon is shallow ( 0.4 to $1.7 \mathrm{~m}$ ) to the north of Hountigonmè where silt has accumulated and the lagoon edge is convex. This is due to slower bottom currents oriented tangentially towards the bank, favouring the deposition of fine sediment (Rossi, \& Blivi 1995, Reineck, \& Singh 1973; Ferguson, \& Rennie 2017). Near the village of Hounvè, the current velocity and bottom depth are significant. The identified silt suggests settling in a basin during the period of flooding when the strength of the current decreases (Bio Djara, 2018).

\section{- Sector from Place of January 10th to Avlo}




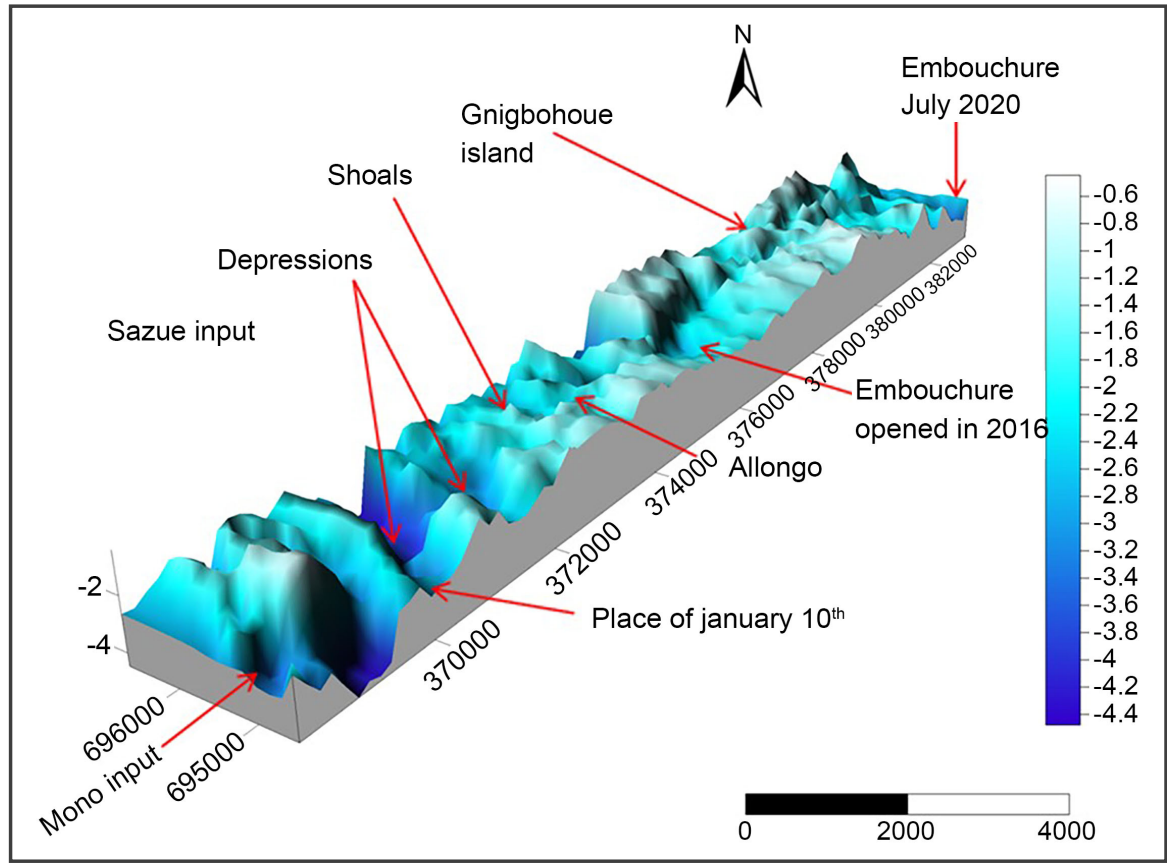

Figure 12. Digital terrain model of the bottom of the Grand-Popo lagoon.

The bathymetric data show that the lagoon bottoms in the sector from Place of January $10^{\text {th }}$ to Avlo is generally shallower $(0.40$ to $1.75 \mathrm{~m})$. These bottoms are full of small basins between Kignontin and Allongo and locally on the edge of the grey sand bar at the latitude of the village Agonnékaney (Figure 12).

The morphology shows an uncharacteristic flat-bottomed trend, suggesting an evolution towards a sedimentary equilibrium. We first note an increase in liquid flows coming from the 10 January square, which increases from $114 \mathrm{~m}^{3} / \mathrm{s}$ to 159 $\mathrm{m}^{3} / \mathrm{s}$, then a progressive decrease from the entrance to the basin located between Kignontin and Allongo with a flow going from 90.8 to $76.9 \mathrm{~m}^{3} / \mathrm{s}$. The distribution of the current and the facies identified reflect the morphology of the bottom. Sands cover the sector between the Place of January 10th and Avlo and as one approaches the basin between Kignontin and Allongo, the sediments become muddy sand, sandy mud and then mud. The water velocity is initially slowed down before a new impulse to the west of Avlo beach.

\section{- Sector from Avlo to the east}

This sector extends between the mouth opened in 2016 and the current mouth (2020). The bottoms are of the "V" type, reflecting the erosive action of marine currents. The liquid flows measured are $63 \mathrm{~m}^{3} / \mathrm{s}$ with high velocities exceeding $1.43 \mathrm{~m}^{3} / \mathrm{s}$ at the embouchure and opposite the island of the village Gnigbohoué. The greatest depths $(4-6.40 \mathrm{~m})$ are recorded in this sector. The sediments are mainly sandy, but deposition by settling of fluid silt inside the basin formed near the mouth of 2016 after its closure.

\section{Conclusion}

The Grand-Popo lagoon connects the waters of the Mono River to the Atlantic 
Ocean through a basic river-lagoon zone. Its functioning is influenced by water from the Mono River, the Sazué River and the ocean through the embouchure (or gateway) of the "Bouche du Roy". The latter experiences a west to east migration with an average speed of $170 \mathrm{~m}$ per year (Laîbi, 2011). The fluvial-lagoon salinity indicates an increasing west-east gradient linked to the hydrological regime with an average of 0.24 . Indeed, salinity values are zero on the western side but reach 0.78 in the central part before 7\%o exceeding near the mouth. The PH of the lagoon water, which varies between 7.2 and 7.9, indicates a slightly basic character. The depths of the lagoon bottom, ranging from 0.4 to $6.5 \mathrm{~m}$, seem to be uniformly distributed and show lagoon bottom morphologies of type $\mathrm{V}$ and type $U$, which reflect acute concavities marked by erosion under the effect of the strong current or by a continuous supply of sediments by the Mono River. The currents in the Grand-Popo lagoon vary from 0.005 to $1.43 \mathrm{~m}^{3} / \mathrm{s}$ and the water surface varies between 0.1 and $5.2 \mathrm{~m}$ during the flood period, compared to a smaller variation of 0.06 to $1.7 \mathrm{~m}$ during the low water period. The bottom sediments reveal facies of free sand, muddy sand, sandy mud and mud, with random distribution but in relation to the intensity of the water currents and the depth of the lagoon bottom. Considering the complexity of this lagoon system, it is recommended that the lagoon complex be periodically monitored hydrologically and bathymetrically in order to locate exceptional variations in water levels. This monitoring will make it possible not only to prevent the risks of overflowing lagoon waters and the floods that follow but also the spectacular erosion of the lagoon banks. Indeed, as a preventive measure, measures to stabilise the banks by adding sediment or artificially opening the mouth can be envisaged.

\section{Conflicts of Interest}

The authors declare no conflicts of interest regarding the publication of this paper.

\section{References}

ACL Consultant (2016). Environmental and Social Impact Assessment of the Coastal Protection Project between Hillacondji and Grand-Popo (167 p.). Study Report.

ADELAC (2019). Study on the Hydrological Modeling of Lake Aheme and Its Channels (57 p.). Study Report.

Bio Djara, M. (2018). Benin Beach Morphodynamics and Impacts of Coastlines Developments on the Dynamics Coastline in Benin Embayment (pp. 60, 185). PhD, University of Abomey-Calavi.

Ferguson, S. P., \& Rennie, C. D. (2017). Influence of Alluvial Cover and Lithology on the Adjustment Characteristics of Semi-Alluvial Bedrock Channels. Geomorphology, 285, 260-271. https://doi.org/10.1016/j.geomorph.2017.01.040

Kaki, C., Oyédé, L. M., \& Yessoufou, S. (2001). Sedimentary Dynamics and Coastal Environment of the Beninese Coastline East of the Mouth of the Mono River. Journal de la Recherche Scientifique de l'Université de Lomé, 5, 247-261.

Kombieni, A. (2016). Environmental and Socio-Economic Impacts of Lagoon Sand Exploitation in Grand-Popo District (Benin) Geography Revue of Ouaga I University Pr 
Joseph KI-ZERBO Nº5-Oct. 2016, Vol. 2.

Laîbi, R. A. (2011). Current Dynamics of Estuarine River Embouchure with Sand Spit, "Bouche du Roi", Benin, Gulf of Guinea: Hydrosedimentary and Geomorphological Characterization (277 p. + Appendices). Unique PhD Thesis Carried Out in Alternation between the Univ. of Abomey-Calavi (Benin) and the Univ. du Littoral Côte d'Opale (ULCO, France).

Maanan, M. (2003). Sedimentological Study of Sidi Moussa Lagoon Filling (Atlantic Coast of Morocco) Granulometric, Mineralogical and Geochemical Characterizations (119 p.). Thesis of PhD in Geology Specialty: Sea Geosciences.

Norda Stello et BCI Consults (2016). Study of Coastline Evolution between Hilacondji and Djondi from Landsat Images between 1984 and 2016 within Framework of Technical Study on the Coastal Erosion of the Hilacondji-Grand-Popo Segment Project n/ref: 113912.001-000/v/ref: DP N01/DP/PUGEMU/2016(21 p.).

Oyédé, L. M. (1991). Current Sedimentary Dynamics and Messages Recorded in Quaternary and Neogene Sequences. Benin Margino-Littoral Domain Quaternary and Neogene Sequences (West Africa) (302 p.). PhD University of Bourgogne.

Oyédé, L. M., Kaki, C., \& Laïbi, R. A. (2007). Sedimentary Environment, Morphology et Facies of Lake Aheme in the South-West Beninese Lagoon Complex (Benin, West Africa). Agronomics Sciences Annals of Benin, 9, 75-99.

Reineck, H. E., \& Singh, I. B. (1973). Depositional Sedimentary Environments (439 p.). Springer-Verlag. https://doi.org/10.1007/978-3-642-96291-2

Rossi, G. (1996). Impact of Dams in the Mono Valley (Togo-Benin). Management of Uncertainty. Geomorphology: Relief, Process, Environment, 2, 55-68. https://doi.org/10.3406/morfo.1996.878

Rossi, G., \& Blivi, A. B. (1995). Consequences of Hydraulic Developments in the Mono Valley (Togo-Benin). Are We Able to Manage the Future? Cahiers d'Outre-Mer, 48, 435-452. 